\title{
Does lung function predict the risk of disability pension? An 11-year register- based follow-up study
}

\author{
Irmeli Lindström ${ }^{1 *}$, Paula Pallasaho ${ }^{2}$, Jouko Remes ${ }^{3}$, Tuula Vasankari ${ }^{4,5}$ and Markku Heliövaara ${ }^{6}$
}

\begin{abstract}
Background: Spirometry is widely used in medical surveillance in occupational health and as a diagnostic test for obstructive and restrictive lung disease. We evaluated the effect of spirometry parameters on the risk of all-cause disability pension in a follow-up study of an occupationally active general population-based cohort.

Methods: We measured the pulmonary function of 3386 currently working participants of the Health 2000 Survey in the clinical phase at baseline using spirometry. We obtained the retirement events of the cohort from the nationwide register for 2000-2011. Cox proportional hazards models were used to determine disability pensions.

Results: At baseline, we identified 111 (3.3\%) participants with obstructive spirometry, 95 (2.8\%) with restrictive spirometry, and 3180 controls without restriction or obstruction. The age, sex, educational level, body-mass index, co-morbidities ( 1 or $\geq 2$ ), and the smoking-adjusted hazard ratio of disability pension was 1.07 (95\% confidence interval, $\mathrm{Cl}$ 0.64-1.78) for those with obstructive spirometry, and 1.44 (95\% Cl 0.89-2.32) for those with restrictive spirometry. As continuous variables, and divided into quartiles, the risk of the lowest quartile of forced ventilation capacity (FVC)\% of predicted was $1.49(95 \% \mathrm{Cl} 1.10-2.01)$ and forced expiratory volume in one second (FEV $)_{1} \%$ of predicted 1.66 (95\%Cl: 1.23-2.24) in comparison to the highest quartile in the adjusted models.

Conclusions: Obstructive or restrictive spirometry did not predict disability pension when dichotomized classified variables (normal compared to abnormal) were used. As continuous variables and when divided into quartiles, lower lung volumes showed an increase in the risk of disability pension. Physicians should take this into account when they use spirometry as a prognostic factor of work disability.
\end{abstract}

Keywords: Population-based, Follow-up, Spirometry, Lung disease, COPD, Asthma, Disability

\section{Background}

Spirometry is used in medical surveillance in occupational health and as a diagnostic test for obstructive and restrictive lung disease. The most important parameters are forced expiratory volume in one second $\left(\mathrm{FEV}_{1}\right)$ and forced ventilation capacity (FVC). Obstructive impairment is defined as having $\mathrm{FEV}_{1}$ in ratio to FVC declined $[1,2]$. $\mathrm{FVC}$ is declined in restrictive disorders, and $\mathrm{FEV}_{1}$ is typically equally declined, thus $\mathrm{FEV}_{1} / \mathrm{FVC}$ remains normal. If both $\mathrm{FEV}_{1} / \mathrm{FVC}$ and $\mathrm{FVC}$ are normal, the spirometry is normal, or only slightly abnormal.

\footnotetext{
* Correspondence: Irmeli.lindstrom@ttl.fi

${ }^{1}$ Occupational Medicine, Finnish Institute of Occupational Health,

Topeliuksenkatu 41 B, 00250 Helsinki, Finland

Full list of author information is available at the end of the article
}

Spirometry is the most important diagnostic tool for obstructive lung disease, and $\mathrm{FEV}_{1} / \mathrm{FVC}$ typically declines in prebronchodilator spirometry in obstructive lung diseases. In asthma, in contrast to chronic obstructive pulmonary disease (COPD), lung function may normalize after introducing a bronchodilator or inhaled corticosteroids [3]. The most common cause of mild restriction is obesity. Restriction is typical in lung parenchymal diseases, which are rare in the general population. Sarcoidosis is the most common of these. Spirometry can be normal in milder forms of asthma and lung parenchymal diseases [3]. Thus, the specificity of obstruction or restriction in the prebronchodilator spirometry is low in any lung disease. The sensitivity of prebronchodilator spirometry is high only in COPD, when obstruction is detected [4]. Postbronchodilator spirometry

(c) The Author(s). 2020 Open Access This article is distributed under the terms of the Creative Commons Attribution 4.0 International License (http://creativecommons.org/licenses/by/4.0/), which permits unrestricted use, distribution, and reproduction in any medium, provided you give appropriate credit to the original author(s) and the source, provide a link to the Creative Commons license, and indicate if changes were made. The Creative Commons Public Domain Dedication waiver (http://creativecommons.org/publicdomain/zero/1.0/) applies to the data made available in this article, unless otherwise stated. 
is however always needed to confirm the diagnosis of COPD.

Obstructive lung diseases, asthma and COPD are common health problems among the working-age population and may cause work disability. Follow-up studies have shown that asthma increases the risk of long-term disability [5] and being non-employed [6]. Patel et al. estimated a workforce participation range of 56 to $60 \%$ among individuals with COPD and of 65 to $77 \%$ among individuals without COPD [7]. Earlier cross-sectional studies have shown that self-reported COPD associates with lower self-reported labour force participation [8-13], while a population-based study showed that spirometry-verified COPD had a minor effect on work ability [14]. Register-based studies [15, 16] have also shown that COPD may affect the frequency and cost of disability. Thornton estimated that COPD associated with a decrease of $8.6 \%$ in the likelihood of employment, and an increase of $3.9 \%$ in the likelihood of the use of disability insurance [17].

According to The Finnish Centre for Pensions Register, disability pension was granted to 21,304 individuals in 2016, of which only $72(0.3 \%)$ had asthma and $176(0.8 \%)$ had other respiratory disease as their primary diagnosis for disability pension. The most common causes of disability pension are mental disorders and musculoskeletal diseases [18]. Risk factors for disability pension are higher age, low education, being a woman or unmarried [19, 20], physical or psychosocial workload [21], and adverse health behaviour [2224]. Work-related factors also predict disability pension: for example long work hours, noise exposure, uncomfortable work postures, repetitive or continuous muscle strain, job dissatisfaction, and lack of supervisor support [25].

Our study was carried out among occupationally active people in a nationally representative sample of Finns. Our aim was to find out the impact of spirometry on the risk of all-cause disability. We wanted to know which parameters are the most important predictors of disability and how a physician should interpret spirometry in order to find workers at an increased risk of disability pension and in need of work ability support. We studied whether 1) different spirometric parameters dictomized as normal or abnormal predict disability pension, 2) different spirometric parameters as continous variables predict disability pension, 3) obstruction or restriction is a more important predictor.

\section{Methods}

\section{Study population}

This study was based on the nationally representative Health 2000 Survey, which was carried out in Finland between August 2000 and June 2001 [26, 27]. The population sample of Finnish adults aged 30 or over was formed using a two-stage cluster sampling method [28]. Mainland Finland was divided into five geographical strata based on university hospital districts. In the first stage of sampling, 80 health centre districts (clusters) were selected, and the second stage involved individuals from these districts. The survey had several phases, including many questionnaires, an extensive face-to-face home interview, laboratory and functional capacity tests, and a clinical examination.

We used Vitalograph bellow spirometers (Vitalograph Ltd., Buckingham, UK) to measure lung function. We recorded $\mathrm{FEV}_{1}$ and $\mathrm{FVC}$, using the highest readings from at least two technically valid measurements, in accordance with the guidelines [29]. Pulmonary function varies with age, standing height, sex and ethnicity. Therefore, test results need to be compared to the predicted values and lower limits of normal (LLN). We used the global GLI2012 reference values [2] and defined obstruction as having an $\mathrm{FEV}_{1} / \mathrm{FVC}$ below LLN, and restriction as having an FVC below LLN. We used the baseline values, because the bronchodilatation test was performed on only part of the study population.

The severity of airflow obstruction was determined on the basis of $\mathrm{FEV}_{1} \%$ of predicted using the Global Initiative for Chronic Obstructive Lung Disease criteria [4].

A total of 8028 people were sampled, but 51 died before the data was collected. The final sample included 7977 participants, of whom 6986 (88\%) were interviewed and $6354(80 \%)$ participated in a health examination [28]. Our study population consisted of those 3386 participants who at the time of baseline examination in 2000-2001 were 1) 30 to 63 years old and 2) full- or part-time employed, and 3) participated in the health examination, including spirometry. We did not include older participants, because the normal retirement age in Finland is 63 , and after this it is no longer possible to obtain disability pension. The non-participants in the clinical examinations $(n=385)$ were slightly younger (mean age 42.8 years vs. 44.4 years), more often male (59.2\% vs $49.3 \%)$, current smokers $(40.5 \%$ vs $31.5 \%)$, and had physician-diagnosed asthma less frequently $(6.0 \%$ vs $6.6 \%)$ than the participants $(n=3447)$.

\section{Study groups}

We first divided the study population into three groups based on the spirometry: the Obstructive spirometry group was defined as having an $\mathrm{FEV}_{1} / \mathrm{FVC}$ under LLN in the pre-bronchodilator spirometry. No specific criteria were required for FVC or $\mathrm{FEV}_{1}$. The Restrictive spirometry group was defined as having an FVC under LLN and an $\mathrm{FEV}_{1} / \mathrm{FVC} \geq \mathrm{LLN}$ in the pre-bronchodilator spirometry. The Controls were defined as having no obstruction and no restriction in spirometry, i.e. $\mathrm{FEV}_{1} / \mathrm{FVC} \geq \mathrm{LLN}$ and $\mathrm{FVC} \geq \mathrm{LLN}$ in pre-bronchodilator spirometry.

We then studied the whole population using the spirometry parameters as continuous variables. 


\section{Disability pensions}

The Finnish Centre for Pensions Register provided complete information on all retirement events and their primary and secondary diagnoses granted by the independent pension institutions. All pensions granted before December 31, 2011 were linked to the Health 2000 data by each participant's personal identification number. The follow-up time of retirement events began when a participant completed the questionnaire and ended when one of the following occurred: 1) retirement due to disability pension, 2) retirement due to other reasons (for example age or unemployment), 3) the end of the follow-up period (December, 312,011), or 4) death.

In Finland, a person with a physician-verified chronic illness, disability, or injury, which has been evaluated as causing considerably reduced work ability, is entitled to a part-time or full-time disability pension [30]. The main outcome of this study was retirement due to disability pension, including permanent, temporary, and part-time disability pensions, as well as individual early retirement pension', which was available until 2005 for employees born before 1944 who had a long working career and whose work ability was substantially reduced, but who did not fulfil the criteria for disability pension. The primary and secondary diagnosis of disability pension were registered and coded on the basis of the International Classification of Diseases and Related Health Problems 10.

\section{Covariates}

Detailed information on the variables is described elsewhere [28]. The parameters described here are based on the questionnaire data, unless otherwise mentioned.

Education. Participants who had completed only comprehensive school or part of high school were classified as having a basic education. Those who had completed vocational school or high-school were classified as having a mid-level education. Those who had completed college or who had some other upper secondary or university degree were classified as having a university-level education.

Asthma was defined as the participant reporting having doctor-diagnosed asthma [31]. Self-reported COPD was defined as the participant reporting having COPD.

Smoking. Participants who had not smoked regularly for at least one year were classified as non-smokers. Exsmokers had smoked for at least one year and quit at least one month earlier. Participants who currently smoked were classified as current smokers.

Cotinine was determined from serum samples collected at baseline and stored at $-20 \mathrm{C}^{\circ}$. The method used to determine cotinine concentrations was a modification of the Nicotine Metabolite RIA kit (Diagnostic Products Corporation, LA, USA). For serum cotinine, a high cut-off point of $100 \mu \mathrm{g}$ was used to separate smokers from nonsmokers, as earlier [27].
Body mass index (BMI) was based on measured weight and height.

Other chronic diseases were defined as having one or more of the following: heart disease (ischemic heart disease/heart insufficiency/heart arrhythmia), stroke, rheumatoid arthritis, chronic low back or neck syndrome, a mental disorder, diabetes, or cancer.

\section{Statistical analyses}

In our preliminary study, we presented the descriptive statistics for participants in three groups as percentages or mean values with standard deviations (SD). After this preliminary study, we fit Cox proportional hazards regression models to the SAS software package (version 9.2; SAS Institute, Inc., Cary, North Carolina). The dependent variable was the first occurrence of any disability pension from 2000 to 2011. Hazard ratios (HR) and confidence intervals $(95 \% \mathrm{CI})$ were calculated to estimate the effect of the determinants on whether disability pension was awarded, and were adjusted for covariates. We formed a combined variable with the following categories: 1) obstructive spirometry without or with restriction, 2) restrictive spirometry, no obstruction, 3) no obstruction and no restriction in spirometry. We used this categorised variable as an independent variable in the models. The last category was used as a reference category. These analyses consisted of a crude model and five other models using the following independent covariates: 1) age and gender, 2) education and BMI, 3) one comorbidity and two or more comorbidities, 4) all the aforementioned, and 5) all the aforementioned and current or previous smoking and serum cotinine of $>100 \mu \mathrm{g}$. We added smoking-related parameters to the model last, because smoking associates closely with obstructive spirometry.

We used Cox proportional hazards regression models with the same adjusting variables as mentioned above, and divided $\mathrm{FEV}_{1} / \mathrm{FVC} \%$ of predicted, $\mathrm{FEV}_{1} \%$ of predicted and $\mathrm{FVC} \%$ of predicted into quartiles (in decreasing order into four groups with an equal number of subjects in each). These groups' risks of disability pension were compared, using the same adjustments. We finally used Cox proportional hazards regression models with the same adjusting variables, and $\mathrm{FEV}_{1} / \mathrm{FVC} \%$ of predicted, $\mathrm{FEV}_{1} \%$ of predicted and $\mathrm{FVC} \%$ of predicted as continuous variables, divided into quartiles in the risk analysis of disability pension.

\section{Results}

We identified a total of 111 (3.3\%) cases with obstructive spirometry and $95(2.8 \%)$ cases with restrictive spirometry at baseline (Table 1). Only one third of participants with obstructive spirometry reported having doctor-diagnosed asthma or COPD. Smoking was common in both the obstructive and restrictive spirometry group. A total of $82 \%$ 
of the participants with restrictive spirometry had a BMI of $\geq 25$.

During an average 9.7-year follow-up period, 362 (10.6\%) participants were granted a disability pension: 16 (14.4\%) participants with obstructive spirometry, 19 (20.0\%) participants with restrictive spirometry, and 327 $(10.3 \%)$ of the controls (Table 2). At baseline, these participants were older, slightly more often women, and had a lower level of education, more co-morbidities, and higher BMI than those with no disability pension. The primary or secondary diagnosis of disability pension was a respiratory disease among only $15(4.1 \%)$ of the retired participants, whereas the most common diagnoses were musculoskeletal and psychiatric disorders.

The age, sex, educational level, BMI, and co-morbidities ( 1 or $\geq 2$ ), self-reported current or previous smoking, and a serum cotinine level of $>100 \mu$ g adjusted HR of disability pension was 1.07 (95\%CI 0.64-1.78) for obstructive spirometry, and 1.44 (95\% CI 0.89-2.32) for restrictive spirometry group in the Cox regression models (Table 3).

When analysing $\mathrm{FEV}_{1} / \mathrm{FVC}, \mathrm{FEV}_{1}$ and $\mathrm{FVC} \%$ of predicted in quartiles with equal number of participants, the risk of disability pension increased gradually as FVC $\%$ of predicted decreased (Table 4, Fig. 1). The risk of FVC \% of predicted of the lowest quartile was 1.49 (95\%CI 1.10-2.01) in comparison to the highest quartile in the models adjusted with the same variables as those used in Table 3. Similarly, $\mathrm{FEV}_{1} \%$ of predicted in the quartiles associated with an increased risk of disability pension: HR 1.66 (95\%CI: 1.23-2.24) in the lowest quartile when compared with the highest, whereas the risk of $\mathrm{FEV}_{1} / \mathrm{FVC} \%$ of predicted was less clear.

As a continuous variable, lower $\mathrm{FEV}_{1}$ and $\mathrm{FVC} \%$ of predicted associated modestly with an increased risk of

Table 1 Characteristics of study groups at baseline and length of follow-up periods

\begin{tabular}{|c|c|c|c|c|}
\hline & Obstructive spirometry $n=111$ & Restrictive spirometry $n=95$ & Controls $n=3180$ & All $n=3386$ \\
\hline Age,mean years, (SD) & $45.9(7.8)$ & $46.2(8.4)$ & $44.2(8.3)$ & $44.3(8.3)$ \\
\hline Males & $57(51 \%)$ & $60(63 \%)$ & $1550(49 \%)$ & $1667(49 \%)$ \\
\hline \multicolumn{5}{|l|}{ Education } \\
\hline Basic & $36(32 \%)$ & $35(37 \%)$ & $686(22 \%)$ & $757(22 \%)$ \\
\hline Mid-level & $35(32 \%)$ & $41(43 \%)$ & $1219(38 \%)$ & $1295(38 \%)$ \\
\hline University & $40(36 \%)$ & 19 (20\%) & $1275(40 \%)$ & $1334(39 \%)$ \\
\hline Doctor-diagnosed asthma & $25(23 \%)$ & $11(12 \%)$ & $187(6 \%)$ & $223(7 \%)$ \\
\hline Self-reported COPD & $8(7 \%)$ & $1(1 \%)$ & $10(0.3 \%)$ & $19(1 \%)$ \\
\hline \multicolumn{5}{|l|}{ Smoking } \\
\hline non-smoker & $30(27 \%)$ & $33(35 \%)$ & 1557 (49\%) & $1620(48 \%)$ \\
\hline ex-smoker & $24(22 \%)$ & $25(26 \%)$ & $646(20 \%)$ & $695(21 \%)$ \\
\hline current smoker & 57 (51\%) & 37 (39\%) & $976(31 \%)$ & $1070(32 \%)$ \\
\hline S-cotinine $\geq 100 \mu \mathrm{g} / \mathrm{l}$ & $59(53 \%)$ & $33(35 \%)$ & $826(26 \%)$ & $918(27 \%)$ \\
\hline \multicolumn{5}{|l|}{ BMl } \\
\hline$<25$ & $61(55 \%)$ & $18(19 \%)$ & $1332(42 \%)$ & $1411(42 \%)$ \\
\hline $25-29.9$ & $37(33 \%)$ & $30(32 \%)$ & $1280(40 \%)$ & $1347(40 \%)$ \\
\hline$\geq 30$ & $13(12 \%)$ & $47(50 \%)$ & $567(18 \%)$ & $627(19 \%)$ \\
\hline \multicolumn{5}{|l|}{$\mathrm{FEV}_{1} \%$ predicted } \\
\hline $\mathrm{FEV}_{1} \geq 80 \%$ & $0(0 \%)$ & $70(74 \%)$ & $1996(63 \%)$ & $2066(61 \%)$ \\
\hline $50 \leq \mathrm{FEV}_{1}<80$ & $109(98 \%)$ & $25(26 \%)$ & $1184(37 \%)$ & $1318(39 \%)$ \\
\hline $30 \leq \mathrm{FEV}_{1}<50$ & $2(2 \%)$ & $0(0 \%)$ & $0(0 \%)$ & $2(0.1 \%)$ \\
\hline $\mathrm{FEV}_{1}<30$ & $0(0 \%)$ & $0(0 \%)$ & $0(0 \%)$ & $0(0 \%)$ \\
\hline Length of follow-up period, mean years (SD) & $9.4(3.0)$ & $8.7(3.5)$ & $9.7(2.8)$ & $9.7(2.8)$ \\
\hline \multicolumn{5}{|l|}{ Co-morbidities } \\
\hline 1 & $37(33 \%)$ & $29(31 \%)$ & $1032(33 \%)$ & $1098(32 \%)$ \\
\hline$\geq 2$ & $25(23 \%)$ & $24(25 \%)$ & $476(15 \%)$ & $525(16 \%)$ \\
\hline Physically active & $66(60 \%)$ & $45(48 \%)$ & 1775 (56\%) & 1886 (56\%) \\
\hline
\end{tabular}

FEV1 forced expiratory volume in one second, FVC forced ventilation capacity, BMI body mass index 
Table 2 Proportion of cases (participants with disability pension) in relation to baseline characteristics

\begin{tabular}{|c|c|c|c|c|}
\hline & Total n/mean & Cases $\mathrm{n} /$ mean & Proportion of cases $\%$ & $P$-value \\
\hline All & 3386 & 362 & 10.7 & \\
\hline \multicolumn{5}{|l|}{ Study groups } \\
\hline Controls & 3180 & 327 & 10.3 & 0.005 \\
\hline Obstructive spirometry & 111 & 16 & 14.4 & \\
\hline Restrictive spirometry & 95 & 19 & 20.0 & \\
\hline \multicolumn{5}{|l|}{ Background variables } \\
\hline Age, mean, years & $44.3(8.3)$ & $48.7(6.6)$ & & $<0.001$ \\
\hline Gender & & & & 0.018 \\
\hline Male & 1667 & 157 & 9.4 & \\
\hline Female & 1719 & 205 & 11.9 & \\
\hline Only basic education & 757 & 127 & 16.8 & $<0.001$ \\
\hline Doctor-diagnosed asthma & 223 & 33 & 14.8 & 0.040 \\
\hline Self-reported COPD & 19 & 6 & 31.6 & 0.012 \\
\hline Chronic brochitis & 106 & 17 & 16.0 & 0.055 \\
\hline Comorbidities & & & & $<0.001$ \\
\hline 0 & 1763 & 111 & 6.3 & \\
\hline 1 & 1098 & 123 & 11.2 & \\
\hline$\geq 2$ & 525 & 128 & 24.4 & \\
\hline \multicolumn{5}{|l|}{ Smoking } \\
\hline Non-smoker & 1620 & 149 & 9.2 & 0.026 \\
\hline Ex-smoker & 695 & 83 & 11.9 & \\
\hline Current smoker & 1070 & 130 & 12.1 & \\
\hline Cotinine $>100 \mu \mathrm{g}$ & 918 & 124 & 13.5 & 0.001 \\
\hline BMI & & & & $<0.001$ \\
\hline$<25$ & 1411 & 115 & 8.2 & \\
\hline $25-29.9$ & 1347 & 151 & 11.2 & \\
\hline$\geq 30$ & 627 & 96 & 15.3 & \\
\hline Physically active & 1886 & 195 & 10.3 & 0.586 \\
\hline
\end{tabular}

$B M I$ body mass index, FEV1 forced expiratory volume in one second

disability pension (HR 0.98 , 95\%CI $0.98-0.99$ and 0.99 , 95\% CI 0.98-0.99, respectively in the adjusted models, data not shown in Tables).

\section{Discussion}

In this 11-year register-based follow-up study of the general population, we found no association between obstruction spirometry or restriction and the risk of disability pension when dichotomized classified variables were analysed. Using spirometry parameters as continuous variables and dividing them into quartiles, FVC - a marker of restriction - associated significantly and stepwise increasingly with a risk of disability pension. A relationship was also detected with $\mathrm{FEV}_{1}$, whereas the association with $\mathrm{FEV}_{1} / \mathrm{FVC}$ - a marker of obstruction - was less clear. To our knowledge, this is the first study to link spirometry results with a prospective follow up of retirement events from National Registers.

Our main finding is that using dichotomized variables classified as normal or abnormal may cause classification bias and underestimate the importance of lung volumes in predicting work disability by spirometry. Classification bias is typical in cohort studies and was related to the explanatory variable in our study. Using continuous spirometric parameters and dividing them into quartiles is better for identifying individuals at an increased risk of disability. Specially FVC \% predicted showed a stepwise increase in the risk of disability when the third, second and lowest quartile were compared to the highest quartile. This refers to a dose-response relationship making FVC \% predicted possibly the most important parameter for predicting disability pension. The specificity and sensitivity of the prebronchodilator spirometry result in 


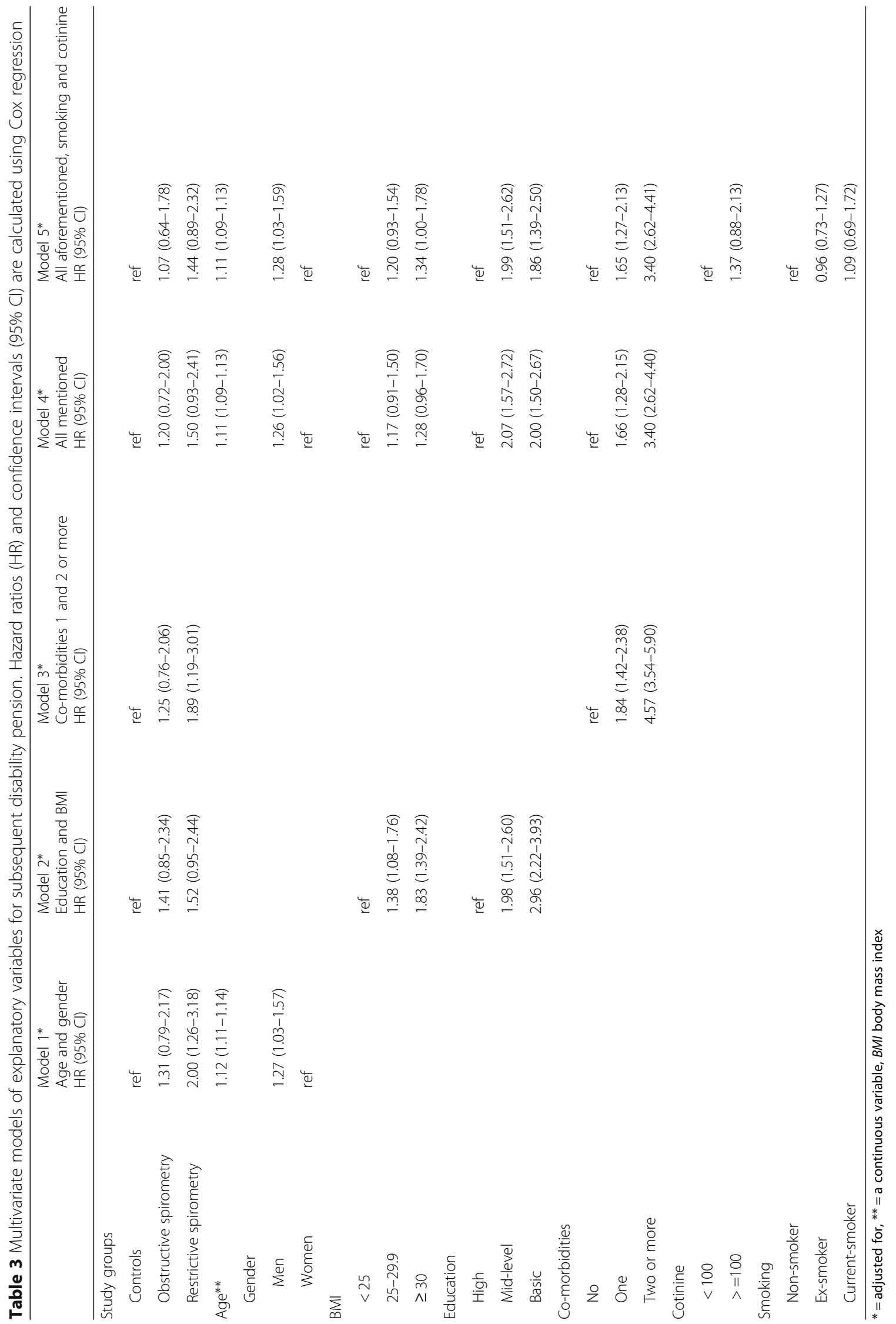




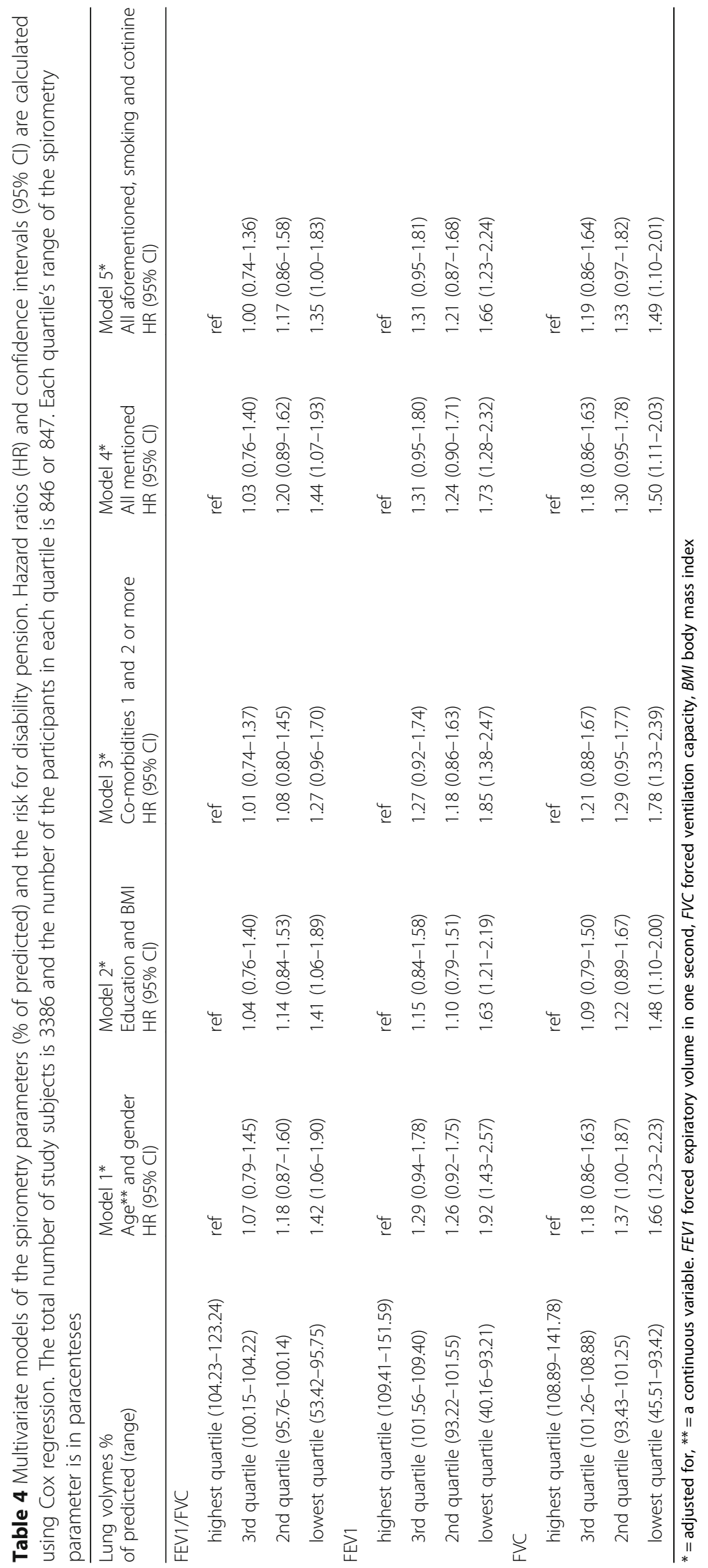



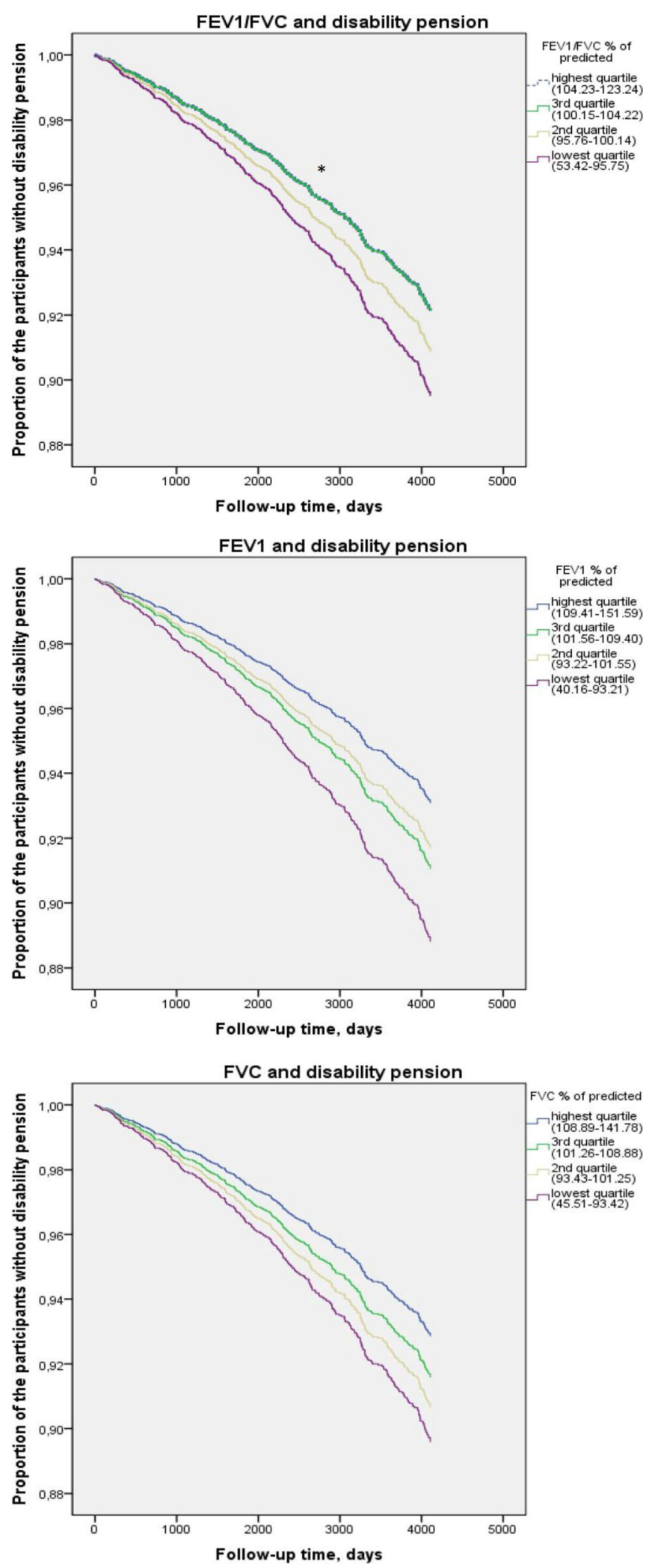

Fig. 1 (See legend on next page.) 
(See figure on previous page.)

Fig. 1 Survival functions for different spirometry parameters and disability pension. The total number of study subjects is 3386 and the number of the participants in each quartile is 846 or 847 . Each quartile's range of the spirometry parameter is in paracenteses. All models are adjusted with age, gender, education level, body mass index, co-morbidities, smoking and cotinine. * In the survival functions of FEV $1 / F V C$ and disability pension highest and $3^{\text {rd }}$ quartile are equal. $\mathrm{FEV}_{1}=$ forced expiratory volume in one second, $\mathrm{FVC}=$ forced ventilation capacity

regard to work limitations is difficult to judge, because it is dependent on the diagnosis of underlining lung disease and its treatment options.

Obstructive spirometry did not associate with the risk of disability pension in our study. The analyses were based on the prebronchodilator test; the cases may partly have reversible obstruction and only some of them true COPD. Obstruction was moderate in $98 \%$ of the cases and only one third of those with obstructive spirometry reported having doctor-diagnosed COPD or asthma. Our findings are in line with Finnish statistics on disability pension, and with Erdal et al., who found that productivity losses were minor in a population-based sample of spirometry-verified COPD [14]. The accumulation of more severe COPD cases in earlier studies with self-reported disease [8-13, $17,32]$ is possible, because COPD typically has a long silent period with deteriorating lung function but no symptoms and may remain undiagnosed. This might have led to overestimation of the effect of COPD on work disability. Longitudinal studies are rare but have shown that smoking predicts retirement due to COPD [33], and that self-reported COPD increases the risk of dependency on one or more activities of daily living [34].

In the age- and gender-adjusted model, restriction in spirometry associated with a 2.0 -fold risk of disability pension in the currently employed general population. Adding education level and BMI to the model reduced this risk to 1.5 -fold. Obesity is a common cause of restrictive spirometry, and in earlier studies, it has shown to predict disability pension [22,35]. Thus, in our study, obesity partly explained the association between restrictive spirometry and disability.

Although we detected no significant relationship between obstruction or restriction as a classified variable in spirometry and disability, we found an association between lower lung volumes as continuous variables and disability. The mechanisms of how low lung volumes affect work ability remain unknown after our study. Low lung function may have an impact on coping in physically demanding work, even if an employee has no lung disease. In previous studies, obstruction in spirometry has been related to all-cause mortality, mortality from cardiovascular and respiratory diseases, and cancer [36].

It is worth noting that the obstructive and restrictive spirometry-associated risk of disability pension changed only slightly when smoking-related variables were added to our models (Table 3). Some studies have shown smoking to be a significant risk factor for disability pension [37, 38]. Haukness et al., however, found that especially among men, this association is mainly explained by the different socioeconomic status of smokers and non-smokers [39]. In our study, only a high serum cotinine level, proving current active smoking, associated with a slightly increased risk of disability pension (Table 3). Self-reported current or previous smoking did not significantly associate with disability pension.

Based on our study, no conclusions can be drawn regarding the prognostic value of spirometry in the risk of disability for individuals with severe lung disease, for example lung fibrosis or severe asthma. Severe lung diseases are rare in the working-age general population, and those suffering from them might have been nonemployed at baseline and thus excluded.

The weakness of our study was the lack of postbronchodilator spirometry results. The participants with fixed obstruction may have been at a greater risk of disability pension, which this study was not able to assess. The other weakness was its relatively small number of participants with obstructive and restrictive spirometry. However, the cohort was carefully selected and the participation rate at baseline was as high as $88 \%$ for the interview and $80 \%$ for clinical examinations. The differences between the participants and the non-participants in the clinical examination were only minor. Thus, we can conclude that our cohort represented the occupationally active general population of Finland in 2000 very well. We took confounding factors into account.

\section{Conclusions}

To conclude, in an occupationally active sample of the general population, obstructive or restrictive spirometry did not predict disability pension when dichotomized classified variables (normal compared to abnormal) were used. When continuous variables were divided into quartiles lower lung volumes showed an increase in the risk of disability pension. Lower lung volumes seemed to have an impact on how people cope in work life. Occupational physicians and other health care providers should take into account declined lung function when, for example, optimizing work tasks, providing care, and considering rehabilitation in order to support work ability.

\section{Abbreviations}

BMI: Body mass index; Cl: Confidence intervals; COPD: Chronic obstructive pulmonary disease; $\mathrm{FEV}_{1}$ : Forced expiratory volume in one second; FVC: Forced ventilation capacity; HR: Hazard ratios; LLN: Lower limits of normal 


\section{Acknowledgements}

We thank Mrs. Ritva Luukkonen for preliminary statistical analyses of the material and The Finnish Work Environment Fund for supporting the study.

\section{Authors' contributions}

All authors have together designed the study, looked through the results, planned the contents of the tables, commentated the different versions of the manuscripts and approved last version of the manuscript. IL is the main author of the manuscript and has made the study plan, ordered the data from National Institute of Welfare, and applied the research grant. PP has applied the permission to the study from the National Institute of Health and Welfare. JR is responsible for statistical analyses. TV has checked the spirometry data. $\mathrm{MH}$ has been involved in the design and performance of the clinical phase of Health 2000 survey. All authors have read and approved the last version of the manuscript.

\section{Funding}

The Finnish Work Environment Fund (grant 114095) and Finnish Institute of Occupational Health have funded the study. The funding bodies have had interest on the study subject. The authors have, however, designed the study and collected, analyzed, and interpreted the data and written the manuscript independently from the funding bodies.

\section{Availability of data and materials}

The study material is available at: https://thl.fi/fi/tutkimus-ja-kehittaminen/ tutkimukset-ja-hankkeet/terveys-2000-2011/tutkimuslomakkeet/terveys-2000tutkimuksen-suomenkieliset-lomakkeet . The datasets used and analysed during the current study are available from the corresponding author on reasonable request.

\section{Ethics approval and consent to participate}

The Ethical Committee for Epidemiology and Public Health of the hospital district of Helsinki and Uusimaa in Finland approved the study. All the participants signed their written informed consent for participating the study and publishing the results.

\section{Consent for publication}

Not applicable.

\section{Competing interests}

The authors declare that they have no competing interests.

\section{Author details}

'Occupational Medicine, Finnish Institute of Occupational Health, Topeliuksenkatu 41 B, 00250 Helsinki, Finland. ${ }^{2}$ Espoo City Health Services, Espoo, Finland. ${ }^{3}$ Statistical Services Team, Finnish Institute of Occupational Health, Helsinki, Finland. ${ }^{4}$ Finnish Lung Health Association (Filha ry), Helsinki, Finland. ${ }^{5}$ Department of Pulmonary Diseases and Clinical Allergology, University of Turku, Turku, Finland. ${ }^{6}$ National Institute for Health and Welfare, Helsinki, Finland.

Received: 7 May 2018 Accepted: 27 January 2020

Published online: 03 February 2020

\section{References}

1. Pellegrino R, Viegi G, Brusasco V, Crapo RO, Burgos F, Casaburi R, Coates A, van der Grinten CP, Gustafsson P, Hankinson J, et al. Interpretative strategies for lung function tests. Eur Respir J. 2005;26:948-68.

2. Quanjer PH, Stanojevic S, Cole TJ, Baur X, Hall GL, Culver BH, Enright PL, Hankinson JL, Ip MS, Zheng J, Stocks J. Multi-ethnic reference values for spirometry for the 3-95-yr age range: the global lung function 2012 equations. Eur Respir J. 2012;40:1324-43.

3. GINA guidelines. 2018

4. GOLD. 2018

5. Hakola R, Kauppi P, Leino T, Ojajarvi A, Pentti J, Oksanen T, Haahtela T, Kivimaki M, Vahtera J. Persistent asthma, comorbid conditions and the risk of work disability: a prospective cohort study. Allergy. 2011;66:1598-603.

6. Thaon I, Wild P, Mouchot L, Monfort C, Touranchet A, Kreutz G, Derriennic F Paris C. Long-term occupational consequences of asthma in a large French cohort of male workers followed up for 5 years. Am J Ind Med. 2008;51: 317-23.
7. Patel JG, Nagar SP, Dalal AA. Indirect costs in chronic obstructive pulmonary disease: a review of the economic burden on employers and individuals in the United States. Int J Chron Obstruct Pulmon Dis. 2014;9:289-300.

8. Fletcher MJ, Upton J, Taylor-Fishwick J, Buist SA, Jenkins C, Hutton J, Barnes N, Van Der Molen T, Walsh JW, Jones P, Walker S. COPD uncovered: an international survey on the impact of chronic obstructive pulmonary disease [COPD] on a working age population. BMC Public Health. 2011;11: 612.

9. Halpern MT, Stanford RH, Borker R. The burden of COPD in the U.S.A.: results from the Confronting COPD survey. Respir Med. 2003;97(Suppl C):S81-9.

10. Kremer AM, Pal TM, van Keimpema AR. Employment and disability for work in patients with COPD: a cross-sectional study among Dutch patients. Int Arch Occup Environ Health. 2006:80:78-86.

11. Sin DD, Stafinski T, Ng YC, Bell NR, Jacobs P. The impact of chronic obstructive pulmonary disease on work loss in the United States. Am J Respir Crit Care Med. 2002;165:704-7.

12. Wang PS, Beck $A$, Berglund $P$, Leutzinger JA, Pronk N, Richling $D$, Schenk TW, Simon G, Stang P, Ustun TB, Kessler RC. Chronic medical conditions and work performance in the health and work performance questionnaire calibration surveys. J Occup Environ Med. 2003;45:1303-11.

13. Ward MM, Javitz HS, Smith WM, Whan MA. Lost income and work limitations in persons with chronic respiratory disorders. J Clin Epidemiol. 2002;55:260-8.

14. Erdal M, Johannessen A, Askildsen JE, Eagan T, Gulsvik A, Gronseth R. Productivity losses in chronic obstructive pulmonary disease: a populationbased survey. BMJ Open Respir Res. 2014;1:e000049.

15. Darkow T, Kadlubek PJ, Shah H, Phillips AL, Marton JP. A retrospective analysis of disability and its related costs among employees with chronic obstructive pulmonary disease. J Occup Environ Med. 2007;49:22-30.

16. Goetzel RZ, Hawkins K, Ozminkowski RJ, Wang S. The health and productivity cost burden of the "top 10" physical and mental health conditions affecting six large U.S. employers in 1999. J Occup Environ Med. 2003;45:5-14.

17. Thornton Snider J, Romley JA, Wong KS, Zhang J, Eber M, Goldman DP. The disability burden of COPD. COPD. 2012;9:513-21.

18. Kaila-Kangas L, Haukka E, Miranda H, Kivekas T, Ahola K, Luukkonen R, Shiri R, Kaaria S, Heliovaara M, Leino-Arjas P. Common mental and musculoskeletal disorders as predictors of disability retirement among Finns. J Affect Disord. 2014;165:38-44.

19. Bruusgaard D, Smeby L, Claussen B. Education and disability pension: a stronger association than previously found. Scand J Public Health. 2010;38: 686-90.

20. Samuelsson A, Ropponen A, Alexanderson K, Lichtenstein P, Svedberg P. Disability pension among Swedish twins--prevalence over 16 years and associations with sociodemographic factors in 1992. J Occup Environ Med. 2012;54:10-6.

21. Lahelma $E$, Laaksonen M, Lallukka T, Martikainen P, Pietilainen $O$, Saastamoinen P, Gould R, Rahkonen O. Working conditions as risk factors for disability retirement: a longitudinal register linkage study. BMC Public Health. 2012;12:309.

22. Neovius K, Johansson K, Rossner S, Neovius M. Disability pension, employment and obesity status: a systematic review. Obes Rev. 2008;9:572-81.

23. Ropponen A, Silventoinen K, Koskenvuo M, Svedberg P, Kaprio J. Stability and change of body mass index as a predictor of disability pension. Scand J Public Health. 2016:44:369-76.

24. Salonsalmi A, Laaksonen M, Lahelma E, Rahkonen O. Drinking habits and disability retirement. Addiction. 2012;107:2128-36.

25. Krause N, Lynch JW, Kaplan GA, Cohen RD, Goldberg DE, Salonen JT. Predictors of disability retirement. Scand J Work Environ Health. 1997;23(6): 403-13

26. Aromaa A, Koskinen S, editors. Health and functional capacity in Finland: baseline results of the Health 2000 health examination survey. Publications of the National Public Health Institute B3, Helsinki. 2004. http://www. terveys2000.fi/publications.html.

27. Vasankari T, Jousilahti P, Knekt P, Marniemi J, Heistaro S, Lppo K, Heliovaara M. Serum cotinine predicts bronchial obstruction regardless of self-reported smoking history. Scand J Public Health. 2011;39:547-52.

28. Heistaro S: Methodology report. The Health 2000 Survey. In Publications of the National Public Health Institute B26; Helsinki; 2008.

29. Standardization of Spirometry, 1994 Update. American Thoracic Society. Am J Respir Crit Care Med. 1995;152:1107-36. 
30. Gould R, Ilmarinen J, Järvisalo J, Koskinen S (Eds.): Dimensions of Work Ability, Results of the Health 2000 Survey. Helsinki: Finnish Centre for Pensions (ETK), The Social Insurance Institution (Kela), National Public Health Institute (KTL), Finnish Institute of Occupational Health (FIOH); 2008.

31. Torén $\mathrm{K}$, Brisman J, Järvholm B. Asthma and asthma-like symptoms in adults assessed by questionnaires. A literature review. Chest. 1993;104(2):600-8.

32. Blanc PD, Eisner MD, Trupin L, Yelin EH, Katz PP, Balmes JR. The association between occupational factors and adverse health outcomes in chronic obstructive pulmonary disease. Occup Environ Med. 2004;61:661-7.

33. Koskenvuo K, Broms U, Korhonen T, Laitinen LA, Huunan-Seppala A, Keistinen T, Autti-Ramo I, Kaprio J, Koskenvuo M. Smoking strongly predicts disability retirement due to COPD: the Finnish twin cohort study. Eur Respir J. 2011;37:26-31.

34. Martinez $\mathrm{CH}$, Richardson CR, Han MK, Cigolle $\mathrm{CT}$. Chronic obstructive pulmonary disease, cognitive impairment, and development of disability: the health and retirement study. Ann Am Thorac Soc. 2014;11:1362-70.

35. Neovius K, Johansson K, Kark M, Neovius M. Obesity status and sick leave: a systematic review. Obes Rev. 2009;10:17-27.

36. Mattila T, Vasankari T, Kanervisto M, Laitinen T, Impivaara O, Rissanen $\mathrm{H}$, Knekt P, Jousilahti P, Saarelainen S, Puukka P, Heliovaara M. Association between all-cause and cause-specific mortality and the GOLD stages 1-4: a 30-year follow-up among Finnish adults. Respir Med. 2015;109:1012-8

37. Claessen H, Arndt V, Drath C, Brenner H. Smoking habits and occupational disability: a cohort study of 14,483 construction workers. Occup Environ Med. 2010;67:84-90.

38. Husemoen LL, Osler M, Godtfredsen NS, Prescott E. Smoking and subsequent risk of early retirement due to permanent disability. Eur J Pub Health. 2004;14:86-92.

39. Haukenes I, Riise T, Haug K, Farbu E, Maeland JG. Smokers' increased risk for disability pension: social confounding or health-mediated effects? Genderspecific analyses of the Hordaland health study cohort. J Epidemiol Community Health. 2013;67:758-64.

\section{Publisher's Note}

Springer Nature remains neutral with regard to jurisdictional claims in published maps and institutional affiliations.

Ready to submit your research? Choose BMC and benefit from:

- fast, convenient online submission

- thorough peer review by experienced researchers in your field

- rapid publication on acceptance

- support for research data, including large and complex data types

- gold Open Access which fosters wider collaboration and increased citations

- maximum visibility for your research: over $100 \mathrm{M}$ website views per year

At $\mathrm{BMC}$, research is always in progress.

Learn more biomedcentral.com/submissions 